\title{
CULTURA Y DIVERSIDAD DE FORMAS DE VIDA: LA HOMOSEXUALIDAD ${ }^{1}$
}

\author{
Verónica Undurraga Valdés
}

\begin{abstract}
En este artículo se sostiene que la discriminación hacia las personas homosexuales se explicaría, en parte, por la trasgresión que implica la homosexualidad a los roles que la sociedad asigna a hombres y mujeres. La incomodidad que producen los homosexuales entre los hombres heterosexuales especialmente, se relacionaría con la experiencia de verse expuestos a la mirada de otro hombre como objeto de deseo, situación que se vive como normal por las mujeres, pero que sería ofensiva para un hombre.

La mirada actual a la homosexualidad — se argumenta en estas páginas - está determinada por nuestras concepciones sobre lo que es "natural” y “antinatural”. Sin embargo, estas ideas serían contingentes. A lo largo de la historia y en diferentes sociedades lo que nos ha
\end{abstract}

Verónica Undurraga. Abogada de la Universidad de Chile. Master of Laws (LLM) Universidad de Columbia, Nueva York. Candidata a doctora en derecho por la Universidad de Chile.

${ }^{1}$ Este trabajo tiene su origen en una ponencia de la autora expuesta en el foro “Cultura y diversidad de formas de vida", realizado el 25 de agosto de 2005, en el marco del seminario "El Chile que viene IV" organizado por el Centro de Estudios Públicos y Expansiva. 
parecido natural no coincide con nuestros parámetros actuales. A juicio de la autora, conocer los matices históricos y culturales que han rodeado la experiencia del amor entre dos personas del mismo sexo nos permitiría ampliar la mirada y juzgar esas relaciones con una mirada más fina. Aquí se hace referencia a la propuesta del filósofo contemporáneo Thomas Nagel como una perspectiva de evaluación de las relaciones amorosas que sería concordante con los valores contemporáneos de la igualdad y la inclusión social. Las relaciones naturales serían aquellas consentidas, que se dan en un marco de respeto e igualdad. Lo antinatural estaría representado por lo forzado, lo violento, lo destructivo y excluyente.

E n este trabajo trato brevemente tres aspectos del tema de la homosexualidad. En primer lugar, sostengo que la discriminación que sufren los homosexuales se explica, en parte al menos, por la desigualdad social que existe entre hombres y mujeres. En segundo término me refiero a la idea de lo natural y lo perverso o antinatural, cómo entendemos estos conceptos y qué efectos tiene esa comprensión en la legitimación social, política y jurídica de la homosexualidad. Por último, intento contextualizar históricamente nuestra manera de mirar y entender la homosexualidad. Concluyo que el impacto trasgresor que tiene la homosexualidad en nuestra sociedad es sano porque nos obliga a cuestionar los valores sobre los cuales estamos fundando nuestras relaciones de pareja, sean o no sean éstas heterosexuales. Este cuestionamiento es ineludible y positivo, y las respuestas por construir serán mejores en la medida en que nadie se margine de él.

\section{La discriminación a los homosexuales se explica, en parte al menos, por la desigualdad social entre hombres y mujeres}

Un camino prometedor para provocar una reflexión personal puede ser el identificar cuáles son reacciones más comunes frente a los homosexuales o a la posibilidad de concederles iguales derechos. ¿Por qué es común que los hombres heterosexuales se sientan agredidos cuando los mira un gay? ¿Qué hay detrás del comentario trivial (y estereotipado) de que el problema con las lesbianas no es que sean lesbianas sino que se vistan como macho? (las lesbianas bonitas son objeto de fantasías sexuales mas- 
culinas). ¿En qué se funda la opinión muy corriente que dice que no hay problemas en que los homosexuales vivan su vida, siempre y cuando no anden haciendo alarde de su relación en público? ¿Qué tiene el matrimonio como para que a muchos les resulte especialmente violento que puedan acceder a él los homosexuales?

Hay en la visibilidad homosexual un elemento tremendamente trasgresor de nuestra identidad. El hombre que se siente amenazado por la mirada de un gay siente que aquel que lo mira no lo respeta, lo está mirando como se mira a las mujeres, no a los hombres, lo está tratando de la forma en que él mismo trata a las mujeres. ¿Y por qué eso debiera ser ofensivo? Que un hombre mire a una mujer con algún grado de interés sexual es una actitud muy masculina y normal y la mujer, en general, lo toma como un halago, un refuerzo a su autoestima. Como dice Pierre Bourdieu, el uso del cuerpo tiene una ética, una política, una cosmología. En este episodio el hombre heterosexual se siente degradado por la mirada del gay porque él, como hombre, se supone que es el sujeto que mira y evalúa y no el objeto que es mirado. La mujer en cambio está acostumbrada a vivirse como un ser "percibido,” un "cuerpo para otro”. Esto la mantiene en un estado permanente de dependencia de la mirada del otro, de inseguridad corporal. Ese papel es ofensivo para un hombre; es normal para una mujer. Tan normal que si no la miran o la miran mal, se expresa en las propias emociones de la mujer, que va a sentir vergüenza o ansiedad respecto de su propio valor. Si uno lo piensa bien, esta diferencia en la forma en que se vive ser hombre o mujer es bastante violenta. Es la diferencia entre vivirse como sujeto y vivirse como objeto. Hay una dominación simbólica muy poderosa detrás de eso que se expresa en que, por ejemplo, una mujer muy deportista (en que su cuerpo tiene una finalidad principalmente distinta de ser mirada) es muchas veces vista como poco femenina, o a una mujer intelectualmente poderosa se le diga que tiene "inteligencia masculina"”.

Eso explica también el malestar que se produce cuando las mujeres empiezan a ingresar en espacios laborales típicamente masculinos. El malestar no se produce principalmente porque las mujeres compitan por los puestos de trabajo, sino porque su ingreso feminiza la profesión, le quita estatus. Es lo mismo que pasa cuando un amigo malvado le dice a otro que el auto que este último se acaba de comprar es un auto “de mina”; es la mejor manera para hacer que el desdichado comprador se deshaga del auto sin preocuparse si con ello hace un mal negocio.

${ }^{2}$ Este tema está brillantemente tratado por Bourdieu, Pierre: La Dominación Masculina, 2003. 
Cuando un gay mira a un hombre heterosexual lo está rebajando a la condición de mujer. Está poniendo en tela de juicio su masculinidad. Esto no es un fenómeno moderno. En la Grecia clásica, donde las relaciones sexuales entre hombres eran en general consideradas naturales, se tenía sin embargo gran cuidado en que el joven que tenía un papel pasivo no mantuviera esa pasividad en el tiempo, porque entonces era despreciado por haberse "convertido en mujer"3. La mujer lesbiana, que pasa por la vida sin interesarse en los hombres, sin ofrecerse simbólicamente a ellos con su vestimenta o sus gestos, que puede arreglárselas sin ellos, es, por lo mismo, una amenaza al orden establecido.

La discriminación hacia la persona homosexual y especialmente hacia el hombre homosexual tiene un sustento muy fuerte en este horror a la feminización tan común entre los hombres en nuestra cultura, en esta especie de autoimposición agotadora de tener que afirmar su virilidad permanentemente con "ese esfuerzo desesperado y constante, y bastante patético en su inconsciencia triunfante, que todo hombre debe hacer para estar a la altura de su idea infantil de hombre"4. Este esfuerzo tiene su contrapartida en la angustia que sufren los hombres gays que tratan de esconder su condición ${ }^{5}$. El problema es que como la virilidad en esta lógica está asocia-

\footnotetext{
3 “Cuando se trataba de relaciones entre dos ciudadanos del mismo sexo, no encontramos una condena general, sino en cambio un complejo sistema de condiciones y reservas. Debemos comenzar notando que estas relaciones, incluso cuando involucran a personas de edad similar, siempre suponen roles asimétricos: El erastes o amante es el mayor, el que en forma activa busca y corteja al más joven, llevado por la visión de la joven belleza masculina. Se espera de él que esté sinceramente interesado en el contacto sexual. Este interés y la conducta (activa, penetradora) que sigue de ello se ve como perfectamente normal y natural. El más joven de la pareja, el eromenos o amado, probablemente estará contento de ser objeto de admiración e interesado en beneficios tales como amistad, educación y ventajas políticas que la relación con el erastes puede traer consigo. La relación en este sentido puede involucrar una real reciprocidad de beneficios y afecto mutuo. Pero la norma cultural dicta que el joven no debe tener un interés sexual real en ser penetrado o desarrollar el hábito de disfrutar de esa penetración; eso sería, en efecto, haberse convertido en mujer, y se podría esperar de ello que se le considere incapaz de desempeñar, posteriormente en su vida, el rol activo masculino”, Nussbaum, Martha C.: Sex and Social Justice, 1999, pp. 306-307 (la traducción es mía). Foucault explica que en la Grecia clásica “... un hombre puede preferir los amores masculinos sin que nadie se atreva a hacerlo sospechoso de feminidad, desde el momento en que es activo en la relación sexual y activo en el dominio moral sobre sí mismo”. Véase Foucault, Michel: Historia de la Sexualidad II. El Uso de los Placeres, 2005.

${ }^{4}$ Bourdieu, Pierre: La Dominación Masculina, 2003, p. 90.

${ }^{5}$ La necesidad de integrarse al ambiente de trabajo es una de las explicaciones más comunes para justificar la permanencia "en el clóset”. Sin embargo, como explica una autora, esta decisión es una espada de dos filos: "si sales del clóset, no vas a pertenecer. Pero si te quedas en el clóset, vas a evitar los eventos sociales y el contacto
} 
da a la idea del poder, existe el riesgo de que la afirmación de la virilidad se dé mediante el ejercicio de la violencia. Basta ver los juguetes que se ofrecen a los niños hombres. Basta con conocer que la violencia doméstica es un fenómeno directamente vinculado al ejercicio del poder y al intento de lograr una actitud sumisa de la pareja. El fenómeno universal de las golpizas a los homosexuales, muchas veces realizadas con fines meramente recreativos, tiene la misma motivación de reforzar la propia masculinidad y supremacía del agresor ${ }^{6}$.

\section{¿Qué es lo natural (normal) y qué es lo perverso (anormal)?}

Una idea recurrente en el rechazo o las aprensiones respecto de la homosexualidad es que "no es natural", que va contra "las leyes de la naturaleza”. Se acompaña normalmente esta idea del argumento de la complementariedad de los órganos sexuales femenino y masculino.

Este argumento es muy interesante porque la idea de lo natural se utiliza en forma bastante escurridiza, de manera que intercambiamos los sentidos en el mismo argumento, cayendo a veces en falacias. A veces decimos que es natural aquello que nos viene dado de nacimiento. Otras veces utili-

más personal de manera de mantener tu secreto. A menos que estés dispuesto a vivir una completa mentira, a lo que mucha gente está dispuesta, puedes ser visto como heterosexual, pero distante, frío o antisocial...". Como un abogado gay explica, "los asociados y socios jóvenes tenían familias e historias de guaguas y siendo gay yo no era parte de eso. Era reticente a socializar porque no quería que me preguntaran sobre mi vida social. En el fondo era percibido como alguien que no 'calzaba””. Kendall, Christopher N.: "Homophobia as an Issue of Sex Discrimination: Lesbian and Gay Equality and the Systemic Effects of Torced Invisibility" (1996), citando a Pam Shime: "Homophobia in the Law: The Experiences of Lesbians and Gay Men in the Legal Profession", artículo no publicado. Se puede contactar a su autora en: probono.law@utoronto.ca. La traducción es mía.

${ }^{6}$ Una interesante entrevista hecha por la estación norteamericana PBS (Public Broadcasting Service) a la sicóloga forense Karen Franklin sobre las motivaciones para atacar a los homosexuales puede leerse en http://www.pbs.org/wgbh/pages/frontline/ shows/assault/interviews/franklin.html de la cual destaco este extracto: "Existe la percepción de que el homosexual es una víctima aceptable ... existe la creencia actualmente de que no es tan cool agredir a minorías raciales. No es tan cool atacar a mujeres o judíos. Pero atacar gays es de hecho algo divertido para un montón de gente joven. Es probablemente el último grupo humano que es socialmente admisible agredir. En parte esto se debe a que la discriminación hacia los gays todavía es legal. Eso envía el mensaje a los jóvenes de que si los gays no tienen los mismos derechos en el trabajo, vivienda, tuición de los hijos, en el mundo militar o respecto del matrimonio, algo malo tienen y a nadie le va a importar si nos entretenemos a expensas de ellos” (la traducción es mía). Sobre ataques a homosexuales en Chile se puede consultar http://www.movilh.org 
zamos el término para designar lo que está profundamente arraigado en nuestros hábitos. También lo ocupamos queriendo decir que si algo es natural no se puede cambiar. Y por último, decimos que si algo viene dado de una determinada manera por la naturaleza es mejor no intervenir y dejar que siga siendo así. En este último caso se deduce, de lo que se cree que es la "naturaleza de las cosas", una norma de comportamiento, un deber ser.

Estos distintos sentidos de lo natural y su interacción se pueden ver claramente en el argumento de la doctrina católica sobre homosexualidad, que aprovecho de tomar como un primer ejemplo ${ }^{7}$. Santo Tomás deduce a partir de la observación del reino animal que es natural el impulso hacia el coito heterosexual, lo que asegura la procreación de las especies. Además, que Dios diseñó las partes del cuerpo humano para cumplir funciones específicas, siendo la del pene depositar el semen en la vagina femenina. Concluyó de ello que cualquier otro acto sexual que no estuviera abierto a estos fines de procreación era antinatural. De ese carácter antinatural, Santo Tomás deduce que el acto es contrario al designio divino y por lo tanto también inmoral. Es decir, de la descripción de lo que es natural se deduce una norma moral.

Para la Iglesia, sin embargo, no siempre la naturalidad de una situación implica su moralidad. Porque la Iglesia, aun reconociendo la posibilidad de que la homosexualidad pueda tener un origen biológico (es decir, ser natural, en el primer sentido), afirma que la prueba de esto no afectaría su doctrina sobre la inmoralidad de las relaciones homosexuales. Con una lógica correcta, a mi juicio, la Iglesia aquí nos dice que lo natural en el sentido de "lo que nos viene dado en nuestro equipamiento básico" no determina necesariamente lo que debe ser. Es posible que el ejercicio de la moralidad exija actuar en oposición a lo que son nuestras tendencias naturales. Pero, si esta vez la Iglesia nos llama a no seguir el camino al que pareciera llevarnos nuestra naturaleza, ¿cómo determinamos cuál es el actuar moral? Juan Pablo II contesta: "las inclinaciones naturales tienen una importancia moral sólo cuando se refieren a la persona humana y su realización auténtica”8. Y el desarrollo auténtico de la persona humana se lograría cuando actuamos conforme a nuestra "naturaleza moral”. Como puede apreciarse, el argumento vuelve a fundar la corrección de la conducta en su coincidencia con una

${ }^{7}$ Para la exposición de la doctrina católica me baso fundamentalmente en Finnis, John: "Reason, faith and homosexual acts" (http://www.catholic socialscientists.org/Symposium2Finnismss.htm.), publicado en Finnis, John: "An Intrinsically Disordered Act”, 2003, pp. 89-99. También puede consultarse del mismo autor: “Law, Morality, and 'Sexual Orientation”, 1994, pp. 1049-1076.

8 Juan Pablo II, Encíclica Veritatis Splendor, 6 de agosto de 1993, sección 50. 
idea de naturaleza. Sin embargo, esta vez no se trata de la naturaleza biológica sino de lo que se llama la naturaleza moral de los seres humanos. La Iglesia postula que la razón humana, incluso sin necesidad de fe, dirige a las personas hacia los bienes humanos básicos. Es decir, nuestra naturaleza moral racional (que también sería parte de nuestro equipo innato), el ejercicio de nuestra recta razón, nos mostraría el camino de lo que es bueno y deseable. Uno de los bienes humanos básicos a los que nos dirigiría nuestra naturaleza moral es el matrimonio, un bien intrínseco, no solamente un medio para el logro de otros bienes valiosos como la crianza. Es esta creencia en la naturaleza moral humana universal que lleva a la Iglesia Católica a sostener que su postura puede ser compartida fuera de la comunidad de creyentes. Se puede apreciar en el argumento eclesiástico sobre la homosexualidad el planteamiento de una oposición entre lo que sería la naturaleza biológica eventualmente inclinada a la homosexualidad y la naturaleza moral que la rechazaría.

En otro ámbito, también el esfuerzo de probar que la homosexualidad tiene un origen biológico es un intento asociado a derivar de lo que es natural (homosexualidad genética) una conclusión normativa. Si la homosexualidad tiene un origen biológico, no depende de la voluntad de la persona homosexual y por lo tanto no se la puede castigar o discriminar por ello. Es como la raza o como la ilegitimidad en la filiación. En este argumento la idea de lo natural como lo innato se mezcla con la noción de lo natural como algo que no puede cambiarse y también con lo natural como algo que el derecho debe reconocer. Si se discrimina al homosexual se estaría haciendo una discriminación basada en una condición de la persona, de la cual ésta no es responsable.

Como muestran estos ejemplos, la naturalidad de una situación puede tener connotaciones tanto positivas como negativas, depende de cómo se mire. La Iglesia considera la inclinación homosexual como "intrínsecamente desordenada”, aunque se nazca homosexual. Esa actitud tiene que ver con una visión más general de la sexualidad y de los instintos. Alan Soble divide a los autores, en un uso divertidamente excesivo de los términos, entre aquellos que tienen una metafísica sexual optimista y los que tienen una metafísica sexual pesimista ${ }^{9}$. Quizás en la cultura occidental han primado los metafísicos sexuales pesimistas, que ven la expresión del impulso sexual como peligrosa y deshumanizante. Kant, por ejemplo, sostiene que las personas que se dejan llevar por sus inclinaciones se degradan a una categoría inferior a la animal, entregan su personalidad porque se usan a sí mismas y a otros para satisfacer un impulso animal, se deshumanizan

\footnotetext{
${ }^{9}$ Soble, Alan: "The Fundamentals of the Philosophy of Sex", 2002.
} 
porque pierden el ejercicio de su libertad. En este tipo de pensamiento pesimista sobre el sexo se encauzan una serie de ideas que están presentes en nuestro imaginario, como por ejemplo que seguir el impulso sexual de alguna manera atenta contra nuestras aspiraciones más dignas, que nos puede llevar a una pérdida del control personal que nos hace menos libres y por lo tanto menos humanos, que es una fuerza que nos lleva a hacer cosas que en nuestro sano juicio no hubiéramos querido hacer y, por último, que es un impulso antisocial, peligroso para una vida civilizada.

En cambio, quien adscribe a una metafísica optimista del sexo lo ve como un impulso natural asociado a emociones y experiencias que pueden hacernos felices, como una energía comunicativa entre las personas y por lo tanto fortalecedor de los lazos sociales y, en general, como un regalo que la naturaleza da y que tiene un valor en sí mismo.

Nuestra opinión sobre la regulación de la sexualidad y la legitimidad de las distintas expresiones sexuales está muy determinada por nuestra actitud pesimista u optimista respecto de la sexualidad. En nuestra época y medio parecen coexistir las visiones pesimistas y optimistas. Quizás en el campo de las aspiraciones afectivas prima la idea optimista de que el sexo nos sirve para expresar nuestro ser más íntimo, que es una ocasión de verdadera autenticidad, que es parte integrante del desarrollo de la personalidad, un ejercicio de los derechos humanos a la libertad y la privacidad. En nuestra realidad normativa, sin embargo, que se expresa en reglas sobre educación de los hijos, imposiciones culturales y religiosas, entre otras, hay una inclinación hacia el pesimismo. Sin perjuicio de que los equilibrios puedan variar, la coexistencia de estos dos polos parece inevitable. La tensión entre la necesidad del individuo de expresarse libremente y la de la sociedad de acotar estas expresiones es precisamente lo que produce "el malestar en la cultura" que identifica Freud ${ }^{10}$.

\section{Contextualizando nuestra manera de entender la homosexualidad}

La idea de lo que es o no natural nos lleva a un problema. Si uno revisa la historia, e incluso si uno revisa las costumbres actuales de algunas sociedades, se da cuenta de que nuestra idea de lo que es o no natural es muy variable ${ }^{11}$. Hay muchos ejemplos; escojo el siguiente que cita Martha Nussbaum por ser muy elocuente. Se trata de un pasaje tomado de Hierón,

${ }^{10}$ Sigmund Freud, El Malestar en la Cultura y Otros Ensayos, 1973.

11 Este tema ha sido desarrollado por Michel Foucault en su Historia de la Sexualidad II. El Uso de los Placeres (traducción de Tomás Segovia), 2005. Ver, por ejemplo, la introducción del tomo II de esta obra. 
de Jenofonte, en que el poeta Simónides y el gobernante de Siracusa, Hierón, del siglo $\mathrm{V}$ antes de Cristo, conversan sobre la pasión erótica.

Pregunta Simónides: “¿Qué quieres decir, Hierón? ¿Me estás diciendo que la pasión erótica por los hombres jóvenes no se da naturalmente en un gobernante, como se da en otras personas? ¿Cómo es entonces que tú estás enamorado de Dailocos?”

Contesta Hierón: "Mi pasión erótica por Dailocos existe porque la naturaleza humana nos compele a desear lo bello, pero yo tengo como fuerte deseo el tener al objeto de mi pasión sólo con su amor y consentimiento" 12 .

Como se aprecia en este diálogo, los dos participantes parten de una afirmación que les parece completamente normal: que es natural la pasión erótica de los hombres por jóvenes bellos. El tema en esta conversación no es la naturalidad de la inclinación a amar a alguien del mismo sexo, que se da por sabida, sino la ética que se impone Hierón al preocuparse de que la relación de amor se base en el afecto y el consentimiento de la pareja y no en el ejercicio de su poder como soberano ${ }^{13}$.

Un segundo ejemplo, de otra época. Alan Bray, historiador eclesiástico de la Universidad de Londres, nos enseña que en la Europa pre-moderna era común y aceptado que parejas del mismo sexo hicieran un compromiso público ante la Iglesia, la que en un rito similar al matrimonio

${ }^{12}$ La cita de Martha C. Nussbaum está en Sex and Social Justice, 1999, p. 254, y se refiere a la obra de Jenofonte, Hierón, en sus párrafos 1.29-38. La traducción es mía.

${ }^{13}$ Por su belleza me parece justificado citar la versión más larga del texto, cuya traducción al inglés se encuentra en la obra editada por Thomas K. Hubbard, Homosexuality in Greece and Rome: A Sourcebook of Basic Documents, y a la que se puede acceder en http://www.utexas.edu/courses/cc348hubbard/readindex.php?view=18/ Dice:

"[29] And the tyrant is at a disadvantage in the pleasures that come from making love to boys even more than in the pleasures that come from begetting children. For we all, presumably, know that making love is by far the most pleasurable if one does it with desire. [30] But desire, in general, comes to a tyrant less easily than to anybody. For desire does not like to aim at available things, but rather at hoped-for ones. Therefore, just as someone who is unacquainted with thirst would not enjoy drinking, in the same way someone who is unacquainted with desire is unacquainted with the sweetest forms of love. [31] That is what Hieron said, but Simonides, having had a laugh, said, "What is that you said, Hieron? You say that desire for boys isn't native to tyrants? How does it then come that you are in love with Daïlochus, whose nickname is 'the loveliest'"? [32] "Because, by Zeus, Simonides," he said, "I do not desire to get from him that which I could obviously have for the asking, but rather that which a tyrant is least likely of anyone to win. [33] For certainly I love Daïlochus on account 
bendecía esa amistad ${ }^{14}$. Da muchos ejemplos, pero uno de ellos es conmovedor y muestra un tipo de amistad que es poco comprensible para nuestra mirada actual, porque está cruzada por toda una cosmología medieval. Bajo el piso de una iglesia dominicana cerca de Constantinopla están enterrados en una misma tumba dos ilustres caballeros de la cámara real de Ricardo II, sir William Neville y sir John Clanvowe. Neville murió cuatro días después de Clanvowe, en octubre de 1391. Según el Westminster Chronicle, Neville después de la muerte de Clanvowe, "por quien su amor no era menor que por sí mismo”, decidió acompañar a su amigo y se dejó morir de inanición. Los escudos de armas de la pareja eran iguales, partidos por una línea vertical, que eran los que usaban las parejas casadas, pero con la particularidad de que cada mitad tenía incrustado un símbolo heráldico que pertenecía a la mitad que representaba al compañero, lo que agrega, a la idea de una unión casi matrimonial, un símbolo adicional de reciprocidad. De acuerdo al rito de la época, Clanvowe y Neville habrían participado en una ceremonia litúrgica, recibiendo la comunión juntos después de haber intercambiado promesas fuera de la Iglesia. Estas promesas, a diferencia del matrimonio heterosexual, tenían efectos estrictamente personales, no afectaban el ámbito patrimonial y ni siquiera impedían el matrimonio heterosexual de alguno de los promitentes. Otorgaban, sin embargo, un reconocimiento al derecho

of those things which human nature compels us to seek from the beautiful. But I very much desire to get the things my love wants from a willing lover, and with friendship. And I think I would want to take them from him by force less than I would want to do myself harm. [34] For I consider that to take from your enemy against his will is the sweetest of all things; but the sweetest of all charms, I think, are the charms of a boy who yields to you willingly. [35] For when a boy loves you in return, how sweetly he looks back at you, how sweetly he asks questions, how sweetly he answers; and the sweetest of all and the most erotic is when he fights with you and argues. [36] But to enjoy the charms of an unwilling boy," he said, "seems to me to be more like robbery than love-making. In fact, a robber at least gets some pleasure from his profits and from making his enemies unhappy; but for a man to take pleasure in the unhappiness of the person he loves and to be hated in return for his love and to force himself on someone he makes miserable: how could this not be a nasty, debasing experience? [37] The private citizen, as soon as the boy he loves does him a favour, has proof that the boy is being kind to him out of love, because he knows that he is doing these things under no compulsion, while it is never possible for a tyrant to feel sure that he is loved. [38] For we know that those who do things for one out of fear do everything they can to make it seem that they act out of friendship. Indeed plots are most often formed against tyrants by none other than those who claim to love them the best".

${ }^{14}$ Bray, Alan: The Friend, 2003. Las referencias a las investigaciones de que trata este libro las obtuve de James Davidson, “Mr. and Mr. and Mrs. and Mr.”, 2005, pp. 13-18. También puede leerse en Internet: Bray, Alan: "Wedded Friendships", The Tablet, 4/8/2001 en: www.thetablet.co.uk/cgi-bin/register.cgi/tablet-00550 
de la pareja a estar presente en ritos familiares y en ocasiones de intimidad, como por ejemplo acompañar en la enfermedad al amigo. Existe cierta ambigüedad en qué tan sexual eran estas relaciones, pero Bray explica que se trata de una época en que distintos tipos de uniones se entrecruzan, en que es difícil hacer la distinción entre una amistad profunda y un amor erótico.

En otras palabras, la ambigüedad de la situación proviene de nuestra percepción moderna, que tiene incorporada la creencia de que las personas son necesariamente heterosexuales u homosexuales. En la época medieval no había un marco mental de ese tipo, como tampoco lo había en la Grecia antigua. Foucault explica que en el griego clásico ni siquiera existía una palabra que denotara algo equivalente a nuestro concepto contemporáneo de sexualidad, sino múltiples términos que aludían a aspectos de lo que hoy consideramos un fenómeno unitario. Como sucedía en la Edad Media, no es que las relaciones entre personas del mismo sexo estuvieran fuera del escrutinio ético, sino que, como dice Foucault, el “campo de problematización” era distinto del nuestro ${ }^{15}$. El concepto de homosexual para referirse a un rasgo de la identidad de una persona se inventó sólo en el siglo XIX ${ }^{16-17}$.

${ }^{15}$ Foulcault, Michel: Historia de la Sexualidad II. El Uso de los Placeres (traducción de Tomás Segovia), 2005, p. 37. En términos coincidentes con la explicación de Foulcault, Nussbaum señala algunas normas éticas que se esperaba que se cumplieran en una relación de este tipo: un ciudadano no podía recibir dinero (o regalos excesivos) a cambio de sexo, se desaprobaba la violencia sexual y la seducción deshonesta, la pasividad como un hábito y la búsqueda del placer sexual con los jóvenes descontextualizada de la amistad y otros valores. Nussbaum, Martha: Sex and Social Justice, 1999, p. 307.

${ }^{16}$ La palabra homosexual se traduce literalmente como "del mismo sexo" y es un híbrido entre el prefijo griego homo —que significa "mismo" (y se distingue de la palabra de raíz latina homo, que significa humano)—y la raíz latina sex — que significa "sexo"- . Hay cierta confusión sobre el origen de la palabra. Una versión señala que el primer uso conocido del término lo habría hecho Karl-Maria Kertbeny, en 1869, en un escrito anónimo titulado "143 des Preussischen Strafgesetzbuchs und seine Aufrechterhaltung als 152 des Entwurfs eines Strafgesetzbuchs f? Norddeutschen Bund" ("Párrafo 143 del Código Penal prusiano y su mantención como el párrafo 152 del Proyecto de Código Penal para la Confederación Alemana del Norte”), que propugnaba la derogación de las normas prusianas sobre sodomía. Esta versión tiene como referencia el libro de Bullough et al. (eds.): Handbook of Medieval Sexuality, 1996. La fuente está citada en http://en.wikipedia.org. Por otra parte, David Halperin señala que el Oxford English Dictionary adjudica a Charles Gilbert Chaddock, un traductor temprano de la obra de Krafft-Ebing Psicopathia Sexualis, el haber introducido la palabra homosexuality al idioma inglés en 1982 "con el fin de traducir a un colega alemán veinte años mayor que él”. David M. Halperin: One Hundred Years of Homosexuality and Other Essays on Greek Love, 1990, p. 15, citado por Michael S. Foldy: The Trials of Oscar Wilde. Deviance, Morality and Late-Victorian Society, 1997, p. 67, nota 2. También de acuer- 
De acuerdo con Joseph Bristow, recién a fines del siglo XIX los investigadores en psicología, medicina y ciencias sociales comenzaron a trabajar con distinciones tajantes entre homosexuales y heterosexuales ${ }^{18}$. Estas distinciones, sin embargo, siguieron siendo polémicas, como queda de manifiesto en el siguiente texto de Freud, escrito en 1920:

La literatura sobre homosexualidad acostumbra no separar los problemas de la elección del objeto de los correspondientes a los caracteres sexuales somáticos y psíquicos, como si la solución dada a uno de estos puntos trajese necesariamente consigo la de los restantes. Pero la experiencia nos enseña todo lo contrario: un hombre, en el que predominan las cualidades masculinas y cuya vida erótica siga también el tipo masculino, puede, sin embargo, ser invertido en lo que respecta al objeto y amar únicamente a los hombres y no a las mujeres. En cambio, un hombre en cuyo carácter predominen las cualidades femeninas y que se conduzca en el amor como una mujer debía ser impulsado por esta disposición femenina a hacer recaer sobre los hombres su elección del objeto, y, sin embargo, puede ser muy bien heterosexual y no mostrar con respecto al objeto un grado de inversión mayor que el corrientemente normal. Lo mismo puede decirse de las mujeres; tampoco en ellas aparecen estrechamente relacionados el carácter sexual y la elección del objeto. Así pues, el enigma de la homosexualidad no es tan sencillo como suele afirmarse tendenciosamente en explicaciones como la que sigue: un alma femenina, y que por lo tanto ha de amar al hombre, ha sido infundida para su desgracia, en un cuerpo masculino, o inversamente, un alma masculina, irresistiblemente atraída por

do al Oxford English Dictionary, la palabra "homofobia” sería un neologismo usado por primera vez en la prensa por el Times Magazine el año 1969 y habría sido acuñado por el sicólogo clínico George Weinsberg en su libro Society and the Healthy Homosexual, 1972.

${ }^{17}$ Incluso respecto de la Inglaterra victoriana se nos advierte que es problemático y técnicamente incorrecto invocar el sentido moderno de homosexualidad como sinónimo de pasión por el mismo sexo, u homosexual para referirse a un individuo que practica la pasión por personas del mismo sexo, porque esa relación era entendida por la sociedad victoriana en forma muy diferente de la nuestra. Véase Foldy, Michael S.: The Trials of Oscar Wilde. Deviance, Morality and Late-Victorian Society, 1997, pp. 67-68.

${ }^{18}$ Bristow, Joseph: "A Complex, Multiform Creature: Wilde’s Sexual Identities”, 1997, p. 198. Para un interesante estudio sobre la dificultad del uso de estos términos en la investigación histórica, véase Boswell, John: "Revolutions, Universals, and Sexual Categories”, 1989. El texto en versión electrónica puede encontrarse en http://hem.passagen.se/nicb/boswell.htm. Última visita 27 de febrero de 2006. 
una mujer, se halla desdichadamente ligada a un cuerpo femenino. Trátase más bien de tres series de caracteres:

Caracteres sexuales somáticos (hermafroditismo físico)

Carácter sexual psíquico (actitud masculina, actitud femenina)

Tipo de elección del objeto

que varían con cierta independencia unos de otros y aparecen en todo individuo diversamente combinados..."19.

Los trabajos de los psicoanalistas de principios del siglo XX en el tema de la homosexualidad nos siguen mostrando que el rol de género se confunde fácilmente, o está íntimamente ligado a la definición de la identidad sexual. Joan Riviere, en un famoso trabajo titulado "La Femineidad como Máscara”, analiza a dos de sus pacientes mujeres que ella identifica (usando una clasificación de Ernst Jones) como parte de un grupo de mujeres homosexuales que, "sin interesarse por otras mujeres, desean ver 'reconocer' su masculinidad y piden ser sus iguales, es decir, ser ellas mismas hombres" (las cursivas son mías). La primera se trata de una profesional que

responde a todos los criterios de una femineidad realizada... [s]us relaciones con su marido eran excelentes, tanto en el plano afectivo como en sus relaciones sexuales, que eran frecuentes y satisfactorias. Estaba muy orgullosa de ser una perfecta ama de casa. Había triunfado notablemente en su profesión. Poseía en el más alto grado la posibilidad de adaptarse a la realidad y había sido capaz de mantener buenas relaciones con casi todas las personas de su entorno... Se trataba de una mujer... profesionalmente dedicada a una carrera de propagandista militante que la obligaba en lo esencial a hablar y a escribir... A pesar del éxito innegable de sus cualidades intelectuales y sus dones prácticos, de su capacidad de interesar al auditorio y de dirigir un debate, era presa generalmente, en el curso de la noche siguiente, de un estado de excitación y de aprehensión, de un temor de haber cometido un error o una torpeza, y sentía una necesidad obsesiva de que la afirmaran. Esta necesidad la llevaba compulsivamente a llamar la atención, o a provocar cumplidos por parte de un hombre, o de varios, a la salida de las reuniones en las que había participado, en el curso de las cuales había desempeñado el papel principal ... trataba de afirmarse: primero, directamente, sobre la base de los cumplidos que se le hacían concernientes a su aparición en público, pero, sobre todo,

${ }^{19}$ Freud, Sigmund: “Sobre la Psicogénesis de un Caso de Homosexualidad Femenina” (1920) 1979, pp. 140-141. 
indirectamente sobre la base del interés sexual que le demostraban esos hombres. Su comportamiento después de estas reuniones estaba destinado a provocar avances por parte de un tipo de hombre particular, coqueteando con él o tratando de seducirlo de manera más o menos velada...”. Su otra paciente era "una mujer inteligente, casada y madre de familia, maestra de conferencias en la Universidad, en una rama difícil en la que pocas mujeres se aventuran. Cuando tenía que dictar un curso, no ante los estudiantes sino ante un auditorio de colegas, se vestía de modo particularmente femenino. En esas ocasiones su comportamiento mostraba algo incongruente. Para dictar el curso adoptaba un tono desenvuelto y bromista, que había provocado muchos reproches y comentarios entre sus colegas. Se sentía obligada a transformar esta situación, en la que tenía un papel masculino, en un juego, en algo no verdadero, en un embuste ${ }^{20-21}$.

Lo extraordinario de este texto es su anacronismo científico y cultural. Eso mismo nos permite darnos cuenta hasta qué medida los términos heterosexual / homosexual se entienden mejor históricamente, no como conceptos estáticos y permanentes, sino como fenómenos socialmente construidos, transitorios y referidos a culturas determinadas ${ }^{22}$.

La importancia de la dificultad de definir qué es un heterosexual o un homosexual trasciende el plano de la teoría. Es en sus manifestaciones fácticas y políticas en que sus efectos pueden llegar a ser dramáticos, como lo demuestran los intentos que se han hecho para castigar penalmente la sodomía, para impedir el ingreso o permanencia de homosexuales en el mundo militar o para evitar conductas homosexuales en los colegios. ¿Qué conductas tendrían que exigirse para calificar una persona de homosexual? ¿Basta con el reconocimiento explícito del afectado? ¿Se requiere como prueba la realización del acto sexual? ¿Tiene éste que ser voluntario? ¿Es

${ }^{20}$ Riviere, Joan: “La Femineidad como Máscara”, 1979, pp. 12-18. El trabajo de Riviere fue publicado por primera vez en The Internacional Journal of Psicoanalisis (IJPA), Vol. 10 (1929). Así como al comienzo de este trabajo nos referimos a la angustia de los hombres heterosexuales por afirmar su masculinidad y al miedo de los gays de que se descubra su homosexualidad no revelada, habría que agregar el estrés que viven las mujeres que ingresan a campos laborales tradicionalmente masculinos, por demostrar que siguen siendo “femeninas." Los "problemas” de las pacientes de Riviere me producen, por lo mismo, una singular empatía.

${ }^{21}$ Estos temas se discuten a propósito de casos judiciales reales estadounidenses en Nussbaum, Marha: Sex and Social Justice, 1999, pp. 186-190.

${ }^{22}$ Foldy, Michel S.: The Trials of Oscar Wilde. Deviance, Morality and LateVictorian Society, 1997, p. 68. 
homosexual el militar que obliga a un conscripto más joven a hacerle favores sexuales? ¿O depende de cuán habitual sea esa solicitud?

Un caso extremo de la incapacidad de nuestros conceptos de heterosexual y homosexual para dar cuenta de la realidad lo proporciona la socióloga y criminóloga de la Universidad de Chile Doris Cooper, en su investigación sobre la homosexualidad en los recintos penales chilenos. Sus estudios muestran, esta vez en forma brutal, las interrelaciones entre la identidad sexual y la percepción cultural de los roles femeninos y masculinos.

En las unidades penales para varones el comportamiento homosexual situacional ${ }^{23}$ se expresa en referencia a dos posibles objetos sexuales, rotulados por los internos como los caballos y los homosexuales de nacimiento o los maricones netos... Se gestan a nivel subcultural penitenciario formas de satisfacción sexual alternativas... surgen en este ámbito nuevos roles, particularmente el de los caballos y de los perkins y se reconoce a la categoría sexual de los homosexuales netos, en el marco del lenguaje del hampa... Los perkins no juegan roles sexuales ... debe desempeñar el rol de empleada doméstica o mujer dueña de casa ... es un rol humillante tanto en unidades penales para mujeres como para varones y en ambas se asocia al rol tradicional de la mujer constituyéndose en un rol social dominado que debe incluso realizar en algunas ocasiones las órdenes más degradantes ... Los homosexuales netos son aquellos homosexuales que en el marco de la percepción social del Hampa (sic), son "maricones de nacimiento" ... Los caballos, en cambio, son "fabricados"... El rótulo de caballo se constituye en un rol-rótulo estigmatizante de un actor social que habiendo sido ladrón (o gil), se le ha cortado la carrera de ladrón en la medida en que se encuentra "roto", es decir violado y usado sexualmente en forma constante por otros internos ... Los caballos cumplen dramáticamente el rol sexual de mujeres ... En ese sentido los caballos no son homosexuales y se constituyen en víctimas de las prácticas sexuales de los internos... Resulta central

${ }^{23}$ Homosexualidad situacional se define como el comportamiento sexual homosexual practicado por actores sociales heterosexuales en situaciones anormales como la reclusión y otras, en las cuales se carece de acceso a la satisfacción sexual heterosexual. Cooper, Doris: Criminología y Delincuencia Femenina, 2002. Al capítulo IX titulado "Comportamiento sexual masculino y femenino intrapenitenciario", del cual se extrajeron los pasajes citados, se puede acceder electrónicamente en: http:// csociales.uchile.cl/publicaciones/biblioteca/docs/personales/comportamiento\% 20sexual\%20femenino\%20y\%20masculino\%20intrapenitenciario.pdf. Última visita 27 de febrero de 2006. 
destacar el hecho de que la existencia de “caballitos" es propia de las unidades penales masculinas, y que si bien las violaciones son delitos también comunes en cárceles de mujeres, no se encuentra ningún rol semejante entre las mujeres presas. En las cárceles de mujeres, la participación en relaciones sexuales lésbicas es en general voluntaria, salvo en las situaciones de violación, y en una baja proporción de casos, algunas mujeres se ven obligadas a participar en relaciones sexuales involuntarias, por "paqueo".

...

[En las cárceles para mujeres] se perciben socialmente cuatro tipos de parejas, correspondientes a las siguientes:

(1) Machos-machos (mujeres con autopercepción de ser varones desde la infancia y con orientación sexual hacia las mujeres) con hembras, es decir mujeres que se autoperciben como mujeres y que tienen orientación sexual hacia los machos $u$ hombres, y que situacionalmente perciben al macho como macho o como hombre. (2) Machos de cartón (mujeres con autopercepción de ser varones tardía y/o situacional, y con orientación sexual hacia las mujeres) con hembras, es decir mujeres que se autoperciben como mujeres y que tienen orientación sexual hacia los machos u hombres, y que situacionalmente perciben al macho como macho o como hombre. (3) Mujeres que se autoperciben como mujeres pero con orientación sexual hacia el mismo sexo, endógena, con mujeres que se autoperciben como mujeres y con orientación sexual lésbica o heterosexual, pero con comportamiento lésbico situacional por necesidad de expresión del instinto sexual. (4) Mujeres que se autoperciben como mujeres, con orientación heterosexual ambas, pero que practican situacionalmente el lesbianismo, como forma de expresión del instinto sexual.

Desde una perspectiva sociológica, es importante destacar el hecho que resulta evidente que las formas habituales de comportamiento sexual normativo bipolar masculino y femenino, se ven importantemente modificadas en situaciones de falta de acceso al comportamiento heterosexual y de una ausencia del control social normativo tradicional, al punto de generarse una subcultura donde comportamientos humanos prohibidos, aparecen como re-normativizados...24.

Son inquietantes todos los ejemplos que he dado. Sugieren que, a veces al menos, todos experimentamos, en mayor o menor medida, el ser mujer o ser hombre como un "hacer” de mujer o "actuar” de hombre. Sin

${ }^{24}$ Cooper, Doris: Criminología y Delincuencia Femenina, 2002. 
embargo, es tan importante para nuestra concepción de la propia identidad el poder definirse como hombre o como mujer que, como elocuentemente lo expresa Judith Butler,

Una es mujer en la medida en que se funcione como tal dentro de la estructura heterosexual dominante, y cuestionar esa estructura significa en alguna medida no saber donde una está situada $^{25}$.

Es decir, no existe un "uno” (un sujeto) que asuma un determinado rol de género. Por el contrario, se necesita “citar” (asumir) un determinado rol de género para que sea recién posible convertirse en "uno”, toda vez que la misma existencia del sujeto depende de la operación previa de legitimar las normas culturales de género ${ }^{26}$. En palabras de Joan Williams, “el género es una de las metáforas que nos permite vivir"27. Y las distintas manifestaciones de la homosexualidad, como instancias de "fluidez" de los géneros son, en ese sentido, desestabilizadoras de nuestra identidad. Como contrapartida, desde “el otro lado", desde la experiencia homosexual que testimonia Butler, la rigidez cultural de los roles de género impide a gays, lesbianas, bisexuales y transexuales tener una identidad legitimada culturalmente.

Para quienes nos sentimos "hallados" en nuestro rol de género femenino o masculino, este rol se vive, la mayor parte del tiempo, como algo natural y deseable. Nuestras vidas "dentro de un género" son parte de lo que Bourdieu llama el hábito. El hábito no nos determina mecánicamente, no impide que seamos creativos. Sin embargo nos arrastra a que casi siempre “escojamos” un camino definido por quienes nos precedieron y por la sociedad en que vivimos. Es una "espontaneidad desprovista de conciencia o voluntad".

Porque el hábito es una infinita capacidad de generar productos - pensamientos, percepciones, expresiones y accionescuyos límites están fijados por las condiciones históricas y sociales de su producción, la libertad condicionada y condicional que él otorga está tan lejos de la creación de una nove-

25 Butler, Judith: Gender Trouble. Feminism and the Subvertion of Identity, 1999 (primera edición, 1990), Prefacio. La traducción es mía.

26 Butler, Judith: Gender Trouble. Feminism and the Subvertion of Identity, 1990, p. 232. Citado por Joan Williams, "From Difference to Dominance to Domesticity: Care as Work, Gender as Tradition”, p. 1.483.

27 Williams, Joan: "From Difference to Dominance to Domesticity: Care as Work, Gender as Tradition”, 1990, p. 1.471. La traducción es mía. 
dad impredecible como lo está de la reproducción mecánica del condicionamiento original ${ }^{28}$.

El espacio intermedio entre el condicionamiento cultural y la posibilidad de la total innovación conformaría el intersticio en que se desarrolla nuestra identidad y libertad personales. Freud diría que es el espacio posible de felicidad, dentro del contexto del malestar cultural. Para los homosexuales, las grietas que se forman en la habitual estructura cultural bipolar de los géneros (femenino y masculino) son espacios que se abren para poder definir una identidad y sentirse libres.

Retomo la discusión sobre "lo natural” y vuelvo a los ejemplos de la Grecia clásica y de los amores medievales. Estos ejemplos los cito porque me parece muy interesante constatar que nuestras ideas sobre la homosexualidad, y nuestros juicios sobre lo que es o no "natural", son inseparables de una forma más amplia que tenemos de mirar el mundo y que esta forma varía en el tiempo y en distintas sociedades ${ }^{29}$. En el citado diálogo de Jenofonte, la relación amorosa está vista en el contexto de una ética sobre el ejercicio del poder y el valor del afecto verdadero (preocupaciones recurrentes en la literatura clásica griega). La tumba de Neville y Clanvowe está teñida de una visión medieval del honor y el heroísmo. La sexualidad se vive en un contexto más amplio que es el que da sentido a las relaciones. Eso también nos sucede a nosotros.

Relaciones como las que describen estos dos ejemplos se miran en nuestra época como desviaciones. Para muchos, son antinaturales. ¿Significa que hemos descubierto ahora el verdadero sentido de lo natural? ¿O tenían razón los griegos y estamos equivocados nosotros? ¿Son ellos o somos nosotros los perversos? Creo que a estas alturas podemos sostener que la pregunta no es atingente, porque lo natural del hombre incluye lo social, son aspectos que crecen juntos, son inseparables. No hay un yo más auténtico en estado de naturaleza bajo mis condicionamientos sociales.

${ }^{28}$ Pierre Bourdieu, The Logic of Practice (Cambridge: Polity Press, traducción de Richard Nice, 1980, 1990, p. 56), citado por Williams, Joan: "From Difference to Dominance to Domesticity: Care as Work, Gender as Tradition”, p. 1.474.

${ }^{29}$ Sobre los factores que influyen en las variadas percepciones que las sociedades tienen de la homosexualidad (ideas sobre los fines de la sexualidad, concepciones sobre la belleza humana, jerarquías de género y clase, etc.), véase Boswell, John: "Revolutions, Universals, and Sexual Categories”, 1989. El texto en versión electrónica puede encontrarse en http://hem.passagen.se/nicb/boswell.htm 
Actualmente entre nosotros lo natural parece ser la heterosexualidad, aunque los supuestos culturales en que esa convicción se basa no están fijos, están en movimiento y podemos estar ante un nuevo cambio de mirada.

Para apreciar este cambio de mirada se puede contrastar el argumento de Santo Tomás con el argumento de filósofo contemporáneo Thomas Nagel. Nagel dice que para descubrir lo que es distintivo de la sexualidad humana y por lo tanto para determinar lo que es natural y lo que es antinatural, no tenemos que fijarnos, como hace Santo Tomás, en lo que tenemos en común con el resto de los animales sino precisamente en lo que no tenemos en común, que es lo propiamente humano. El aspecto que sería lo especial de la sexualidad humana es que las interacciones sexuales se dan a partir de un deseo que crece en una persona al percibir y reconocer el deseo sexual de la otra. Las relaciones antinaturales, para Nagel, serían aquellas en que no hay un reconocimiento mutuo, sino que una persona trata a otra como un objeto en la relación sexual, le priva de subjetividad. Bajo esta concepción de lo natural, los actos homosexuales, mientras cumplieran con esta condición de reconocimiento del otro, serían naturales ${ }^{30}$.

El planteamiento de Nagel nos propone una pauta, quizás más que eso, nos sugiere el lado más luminoso de lo que podría ser un nuevo entendimiento de lo natural y también de lo moral en materia de sexualidad. Pareciera que ahora valoramos especialmente que las relaciones amorosas sean consentidas y se den en un marco de respeto, igualdad y de inclusividad (tenemos una sensibilidad mayor a la discriminación de personas). Lo antinatural sería en ese caso lo forzado, lo violento, lo destructivo, lo peligroso, lo excluyente.

Si esto fuera así, estos nuevos estándares pueden volverse contra nosotros y muchas de nuestras creencias y formas de vida como un boomerang. Porque podemos empezar a evaluar, por ejemplo, las relaciones de amor heterosexual y ver qué tan igualitarias y respetuosas son, cómo vivimos estos valores en el matrimonio, por ejemplo. Más al fondo, cómo armamos nuestra identidad como mujeres y como hombres. Es inquietante, porque si de verdad tenemos tan incorporado el fenómeno de la subordinación en nuestras relaciones heterosexuales como parecieran sugerir los ejemplos que di al comienzo del texto, la trasgresión que supone la homosexualidad es una sana alarma. Plantea, al menos teóricamente, un posible paradigma de relaciones en que el amor se separe del ejercicio del poder, lo que daría esperanzas para terminar con la violencia doméstica y el acoso sexual, entre otras tragedias cotidianas.

30 Thomas Nagel, "Sexual Perversion”, citado por Soble, Alan: "The Fundamentals of the Philosophy of Sex”, 2002, nota 7. 
Esta mirada nos permite a los heterosexuales ser más humildes a la hora de preguntarse “desde la normalidad” por la legitimidad jurídica de las relaciones homosexuales. Un buen punto para empezar a salir del inmovilismo de la perplejidad en que pareciéramos estar sumidos.

Quiero contar otra historia, también relatada por Bray. En el siglo XIX, John Henry Newman, vicario de Saint Mary, en Oxford, y primer rector de la Universidad Católica de Dublín, nombrado cardenal por León XIII, escribió: “deseo con todo mi corazón ser enterrado en la tumba del padre Ambrose Saint John, ésta es mi última e imperativa voluntad”. Y así se hizo en el Oratorio de St. Philip Neri, en 1890. El propio Newman dejó constancia de que su relación con Saint John había sido puramente espiritual. Su fidelidad a las normas eclesiásticas, sin embargo, no fue obstáculo para que se desarrollara entre ellos una amistad verdadera e intensa. Newman escribió “desde el principio él me amó con la intensidad del amor, que era indescriptible”. La muerte de St. John dejó devastado a Newman, quien dijo que la pérdida era "la mayor aflicción que he tenido en mi vida". "Yo siempre pensé que ninguna desolación se comparaba con la del esposo o esposa, pero siento que es difícil de creer que pueda haber una pena mayor que la mía.”

Esta historia conmovedora deja la sensación de que hemos perdido algo valioso en nuestra forma moderna de ver las relaciones humanas. Hay aquí una sensibilidad, una posibilidad de valorar una gama más amplia de relaciones humanas profundas que ha sido aplastada por nuestros juicios tajantes respecto de la moralidad sexual. Conocer historias como las de Neville y Clanvowe, o de Newman y Saint John nos ayuda a recuperar una mirada menos estrecha y menos contaminada por esta especie de obsesión por lo puramente sexual, que es tan propia de nuestra época (y que la debemos probablemente a la metafísica sexual pesimista que ha estado presente durante gran parte de la historia occidental). Se haría más justicia a las relaciones entre mujeres, entre hombres y entre hombres y mujeres, si fueran juzgadas más por su calidad y profundidad individual, que por su pertenencia a categorías burdamente calificadas de morales o inmorales a priori. Hasta ahora parece ser un privilegio de los heterosexuales el que nadie nos defina, a partir de la orientación sexual, el gozar la libertad de configurar nuestra identidad sobre parámetros que nosotros (en la medida de lo posible) escojamos.

En las sociedades occidentales, como lo muestran los cambios legislativos en diversos países, estamos experimentando un cambio en las convicciones en que se ha basado hasta ahora el trato discriminatorio hacia los homosexuales y lesbianas. Es el momento en Chile para avanzar más allá de 
la perplejidad y para esto es imprescindible que todas nuestras sensibilidades estén representadas en el diálogo. Así podremos preguntarnos con prudencia conservadora qué queremos mantener de nuestras tradiciones (miradas éstas sin sesgos quizás nos lleven a recuperar el respeto por relaciones más diversas entre los sexos) y, con idealismo progresista, cómo queremos mejorarlas para hacerlas más igualitarias y asegurar la dignidad de todas las personas.

Termino citando un diálogo tomado de La República de Platón, que también rescata Nussbaum. En él, Sócrates comenta con Glaucón sobre los cambios radicales que Sócrates propone en la estructura de la familia y en el rol de la mujer. Sócrates señala que en general las personas no desarrollan esos temas porque se quedan conformes con los acuerdos que la gente ha ido tomando a lo largo del tiempo y que esos acuerdos son suficientes. Glaucón contesta que las personas actúan así por flojera. "La flojera, sin embargo - dice Sócrates-, es un lujo que los guardianes de las ciudades y las leyes no pueden permitirse." "Eso es probablemente cierto", contesta Glaucón ${ }^{31}$.

\section{BibliografíA}

Boswell, John: "Revolutions, Universals, and Sexual Categories”. En Martin Duberman, Martha Vicinus y George Chauncey, Jr., Hidden from History: Reclaiming the Gay and Lesbian Past. New York: Meridian, 1989. El texto en versión electrónica puede encontrarse en http://hem.passagen.se/nicb/boswell.htm. Última visita 27 de febrero de 2006.

Bourdieu, Pierre: La Dominación Masculina. Anagrama, 3ª edición en español, 2003.

Bray, Alan: "Wedded Friendships". En The Tablet, 4/8/2001. En: www.thetablet.co.uk/ cgi-bin/register.cgi/tablet-00550

Bristow, Joseph: “A Complex, Multiform Creature: Wilde’s Sexual Identities”. En Peter Raby (ed.), The Cambridge Companion to Oscar Wilde. Cambridge: Cambridge University Press, 1997.

Butler, Judith: Gender Trouble. Feminism and the Subvertion of Identity. Nueva York y Londres: Routledge, 1999 (primera edición, 1990).

Cooper, Doris: Criminología y Delincuencia Femenina. Santiago: LOM, 2002.

Davidson, James: "Mr. and Mr. and Mrs. and Mrs". En London Review of Books, Volume 27, No 11, 2 June 2005, 13-18.

Finnis, John: “Law, Morality, and 'Sexual Orientation' ”. En Notre Dame Law Review, 69 (1994).

${ }^{31}$ Platón, La República, 504, citado por Nussbaum, Martha C.: Sex and Social Justice, 1999, pp. 274-275. El texto completo de La República está en inglés en la famosa traducción de Benjamín Jowett en http://www.trentu.ca/ mneumann/sj-txt.htm / Última visita: 28 de febrero de 2006. 
Finnis, John: “An Intrinsically Disordered Act”. En Harvey y Bradley (eds.), Same Sex Attraction: A Parents' Guide. South Bend, IN: St. Augustine, 2003. http:// www.catholicsocialscientists.org/Symposium2-Finnis-mss.htm/.

Foldy, Michael S.: The Trials of Oscar Wilde. Deviance, Morality and Late Victorian Society. Nueva York y Londres: Yale University Press, 1997.

Foucault, Michel: Historia de la Sexualidad II. El Uso de los Placeres. Traducción de Tomás Segovia. Siglo XXI España Editores, 2005.

Freud, Sigmund: El Malestar en la Cultura y Otros Ensayos. Madrid: Alianza Editorial, $2^{\mathrm{a}}$ ed., 1973.

Freud, Sigmund: "Sobre la Psicogénesis de un Caso de Homosexualidad Femenina" (1920). En Alicia Roig (ed.), La Femineidad como Máscara. Barcelona: Tusquets, 1979.

Hubbard, Thomas K.: Homosexuality in Greece and Rome: A Sourcebook of Basic Document. Berkeley: University of California Press, 2003. Se puede consultar electrónicamente en: http://www.utexas.edu/courses/cc348hubbard/ readindex.php?view $=18 /$.

Juan Pablo II, Encíclica Veritates Splendor, 1993.

Kendall, Christopher N.: "Homophobia as an Issue of Sex Discrimination: Lesbian and Gay Equality and the Systemic Effects of Torced Invisibility”. Murdoch University Electronic Journal of Law, Vol. 3 No 3 (September 1996).

Nussbaum, Martha C.: Sex and Social Justice. Oxford University Press, 1999.

PBS (Public Broadcasting Service): Entrevista a la sicóloga forense Karen Franklin sobre las motivaciones para atacar a los homosexuales. Puede leerse en http:// www.pbs.org/wgbh/pages/frontline/shows/assault/interviews/franklin.html

Riviere, Joan: "La Femineidad como Máscara”. En Alicia Roig (ed.), La Femineidad como Máscara. Barcelona: Tusquets, 1979.

Soble, Alan: "The Fundamentals of the Philosophy of Sex". En Alan Soble, The Philosophy of Sex. Rowman and Littlefield, 4a edición, 2002.

Williams, Joan: "From Difference to Dominance to Domesticity: Care as Work, Gender as Tradition”. En Chicago-Kent Law Review, 76 (1990). 